\title{
Communication Challenges in Connection with Catastrophes and States of Emergency
}

\author{
A Review of the Literature
}

\author{
Stig Arne Nohrstedt
}

When catastrophes happen, they generally happen suddenly and have far-reaching consequences. They strike everyone and everything - people, organizations, social institutions - but in different ways and, it should be stressed - they hit some harder than others. When we think of catastrophes we naturally tend to think of the suffering they cause those most directly affected. But there are also consequences of a more indirect nature: material damage, environmental damage, impacts on social relations and on public confidence in authorities and institutions.

The purpose of this review of the literature is to summarize the principal lessons offered by the research to date on communication aspects of catastrophes, i.e., people's need of information, the success and failure of various communication efforts, changes in people's confidence in authorities and mass media, the interaction between media and authorities, etc. Relevant findings from several fields are included: catastrophe communication, risk communication, and communication in emergencies or crises. It should be pointed out, however, that the field is quite heterogeneous, and there is no common denominator in terms of theory or methodology. This is a consequence of the fact that most studies are case studies that have been initiated by the events in question; ambitions to generalize have been secondary at best. Another contributing factor is that researchers from different academic disciplines have applied a variety of theoretical frames of reference.

It should also be noted that the terms catastrophe, risk and crisis are not synonymous or interchangeable. 'Catastrophe' denotes an event having serious negative consequences for many people, whereas 'risk' denotes a presumed or possible threat or danger. 'Crisis', finally, can defined on an individual or a collective level. In this context we will primarily be discussing collective, societal crises, events that threaten central values and call established authority structures into question (cf. Nohrstedt \& Tassew 1993; Flodin 1993). At the end of the review I will discuss the relationships between these phenomena in an interactional perspective involving various crisis factors.

The field of research has grown rapidly in recent decades, both in Sweden and internationally. Perspectives on the role of communication have broadened. Whereas research in the area known as 'risk communication' previously concentrated on the char- 
acter of the risk, today far more complex models that include both physical and social aspects are applied (Gutteling \& Wiegman 1996).

Another purpose of the review is to describe the difficulties people in positions of responsibility, both within public authorities and mass media, face in extraordinary situations like these, and the lessons to be learned from studies of major accidents and catastrophes that have occurred in Sweden over the past twenty years. International research findings will of course be considered, but there is reason to focus on Swedish cases: doing so gives us a measure of the extent to which we here in Sweden actually apply what we have learned from past experience when confronted with new emergencies. ${ }^{1}$

The present review builds substantially on a review of the disaster research literature done in the early 1990s by a group of researchers at the request of the National Board of Psychological Defence Planning (SPF) and the National Defence Research Establishment (FOA) (Flodin 1993; Jarlbro 1993; Nohrstedt \& Nordlund 1993; Nohrstedt \& Tassew 1993). It has been updated with subsequent studies. Nonetheless, due to the heterogeneity of the field the review makes no claim to offering a complete inventory.

It should be noted that the review does not include studies of the technical aspects of catastrophes. The author is a media researcher with training in the social sciences. Since social and media aspects of catastrophes and crises cannot be understood without certain basic knowledge about people's risk perceptions, some findings from studies of risk perception have also been included.

\section{A Sudden Flood of Questions}

Since the word catastrophe can be used to describe a broad spectrum of events having different causes, different courses of development and different consequences, it is quite impossible to describe, in standard terms, how catastrophes affect communication and information processes in society or to say in few words what they can teach us. We can, however, see certain common patterns and conditions which appear to occur rather regularly, whether the event is a fire, an emergency at sea or, say, a nuclear accident. In the following we shall focus on experiences that relate to some of the central communication problems that catastrophes present and the lessons organizations have learned from them.

The principal factor with respect to how catastrophes impact on public information processes is a tremendous surge in people's need of information. The needs may be regarded as an expression of a need to get a grip on the situation, to 'control' or create order in their environment to the extent possible. When catastrophe strikes there arises a need for information about what caused it, its consequences and its victims. The first news of a catastrophe triggers a horde of questions, especially from individuals who may be at risk. The number of questions will, of course, vary widely between, say, a derailment caused by a blizzard (clearly delimited) and radioactive fallout after a nuclear 'excursion' (extent unknown). But although the flood of questions may vary in volume and intensity, the level rises extremely quickly, so quickly that authorities are often hard put to manage the situation.

A prime source of pressure on responsible authorities are news media. News reporters' business is to satisfy the public's need of information as quickly as possible, and they are constantly on 'Red Alert' in case an emergency occurs. As one experienced observer puts it: "Disasters, crises and emergencies can strike suddenly and unexpectedly, anywhere at any time. The causes may be sudden and unpredictable. One factor, however, is certain. The news media will be close behind" (Howarth 1999:xi). Due to the 
media's preparedness, journalists often know more about the situation than the individuals who are responsible for providing information in the most acute phase of the event. This is a source of friction between authorities and the media, but worse, it can develop into a major crisis of confidence (Nohrstedt 1988).

\section{"The Risk Society"}

Modern or 'late-modern' society is characterized by a high degree of risk as a consequence of ongoing processes like urbanization, industrialization and globalization. The successive concentration of populations in metropolitan cities, the use of large-scale and technically sophisticatewd systems for production and distribution, and the rapid integration of previously independent markets and economic systems all imply new, and to some extent unfathomable, threats. It would not be accurate to claim that modern Man faces more or direr risks than our predecessors in, for example, the pre-industrial era, but it is clear that the risks we face today are to a greater extent a consequence of human activity, and that the risks are perhaps more insidious and harder to understand. In addition, we should note that awareness of risk in a general sense has increased, and continues to increase, as a result of research and media reports. It is particularly this latter point - our growing awareness of threats like acidification, the greenhouse effect and radioactive emissions from nuclear facilities of various kinds - that brings Ulrich Beck to speak of "the risk society". Beck's idea is that these new risk scenarios have combined to create a growing feeling of insecurity among the public at large and to reduce public confidence in authorities (Beck 1986).

\section{Disaster as a Process}

Beck's theory offers a frame of reference in which to understand people's sense of vulnerability and their risk perceptions today, even if his ideas are not universally accepted. It must be supplemented if we are to explain people's reactions to hazardous situations. For example, it has been observed that people often actively turn to the responsible authorities for advice and information and then follow their recommendations (Nohrstedt $\&$ Nordlund 1993). Only in exceptional situations does that trust and obedience change to mistrust and turning a deaf ear to authorities' messages.

Behavioural and psychological aspects are not the prime focus of this article, yet a few words have to be said about the most common patterns of cognitive processing and behaviour in response to acute situations. (Unless otherwise noted, the findings are taken from Jarlbro (1993) and works cited in that report.) These shall be noted in connection with several identifiable phases or periods: the planning phase, the warning phase, the acute phase, and the aftermath (consequences and recovery).

During the planning phase, i.e., before the event has occurred or even looms on the horizon, many tend to deny or belittle the risk. Several studies document the difficulty of making the citizenry, and in some cases even authorities, aware of the danger in time, before it is too late. Individuals react differently. Some studies of technological risk perceptions have found that men tend to discount the risk factors more than women do. Studies have also found class differences in that individuals with low incomes and little formal education are more concerned about these kinds of risks than highly educated individuals in high income brackets. Some studies have found that risks to one's own person tend to be discounted, compared to the risk to the population at large. This difference probably has to do with the control aspect. That is to say, where the indi- 
vidual has control over a risk behaviour, such as smoking or drinking, the risk will be considered less for oneself than for others. Dramatic and sensational threats are often considered more likely than they actually are, whereas risks of an everyday nature are more often underestimated. The difference may be due to media coverage of dramatic events.

Recent research on risk perceptions in the USA has found a pattern that has been termed, "the white male effect". White men in the USA have been found to tend to consider the world much less risky than other groups (Finucane \& Slovic 1999:24). This was true regarding a whole range of risks: from smoking and sunbathing to nuclear meltdowns and climatic change. White males consistently considered the risk less than white women, non-white men and non-white women did. The authors test various possible explanations of these findings and offer convincing arguments against the idea that the differences might be a function of differences in levels of knowledge or sex.

First of all, the difference persists when controls for level of formal education are applied; secondly the difference between the sexes does not cross race lines. The judgments of non-white men and women were more similar than those of white men and women. The explanation that Finucane and Slovic give most credence is the fact that white men have more influence or 'control' over their situations and derive more benefit from use of technologies and other risk activities than the other groups do. Consequently, they apply a different measuring stick: "In other words, one's risk perception seems to be related to one's power to affect decisions concerning how the risks are handled. ... Compared to white males, many women and non-white men have considerably less power and control, nor do they derive the same benefits from technology and social institutions. Consequently, they perceive the world around them to be riskier" (Finucane \& Slovic 1993:25f).

When catastrophe looms overhead and the alarm is sounded, we enter into the warning phase. Reactions in this phase vary widely. Some are traumatized; behaviour ranges from apathy to manic hyperactivity. Generally speaking, one may say that warnings are given credence according to the perceived credibility of the sender. Another common pattern is that the warning elicits a wave of information-seeking to check or verify the warning message. This reaction often comes as a surprise to crisis managers, with the result that telephone lines and switchboards and other channels of communication can become jammed.

After the warning phase comes the acute phase. Here again, different reactions may be expected, depending on the nature of the catastrophe. Panic is the reaction that has received the most attention in media and in the research literature. Whereas the media have tended to exaggerate the incidence of panic connected with catastrophes and major accidents, the research shows that such reactions are relatively uncommon and that people often react quite rationally even under extreme stress. The exception to this rule is catastrophic fires. These can fulfil the prerequisites for panic, namely, that the individual feels an acute, mortal risk from which there is no escape.

Another common feature of the acute phase is the spreading of rumours. The lack of information regarding the causes of the situation combined with acute danger give rise to speculation and assumptions in both interpersonal communication and communication between the media and the public. Classical studies offer a mathematical formula for the extent rumours will be spread: the volume of rumour in circulation is assumed to be a function of the importance of the subject to the population involved in the spreading of rumour, multiplied by the degree of uncertainty of the information concerned (Allport \& Postman 1947). If the catastrophe is perceived to be the result of factors that 
still can cause damage to certain people - e.g., a specific social or ethnic group - and reliable and accurate information is in scarce supply, the risk of that rumours or unconfirmed information will be widely spread is overhanging.

After the acute phase comes a period of processing the experience, the aftermath. This phase may see various initiatives for dealing with the situation. Spontaneous or organized activities mobilize those affected by the event and people in the vicinity to pitch in and help one another. Victims of the catastrophe try to incorporate their experiences into their lives and to reinstate their everyday routines. They may seek more information about the causes of the event and/or plan for the eventuality of a similar occurence in the future. But there may also be more destructive reactions and feelings of survivor guilt, aggressions and conflicts between different groups of victims. It is not uncommon in this phase that the search for reasons and explanations turns into a search for the person or persons responsible and perhaps also for scapegoats.

\section{Communication Problems Between Experts and the Public}

As mentioned earlier, different people's risk assessments (the likelihood and seriousness of an event) can differ substantially. A problem the particularly impacts on the communication process surrounding catastrophes and other emergencies is that experts often perceive risks differently from laymen. Many factors contribute: differences in knowledge, degree of vulnerability, personal influence or power, and so forth. Two factors deserve special mention: first, vocabulary or jargon, and second, differences in risk perception.

Experts' jargon is made up of many special terms that laymen have never heard or, in any case, cannot grasp the meaning of. Obviously, this hinders communication. Regardless of the nature of the catastrophe, problems of comprehensibility often arise, and these can have a negative effect on public confidence and trust in responsible authorities and experts. Information gaps especially tend to arise in communicating the findings of technical studies. In Sweden such problems occurred in conjunction with the Chernobyl crisis (patches of fallout scattered over large regions of central and northern Sweden) in 1986 and after the sinking of the ferry, "M/S Estonia", in 1994. Successively changing estimates of the amount of radioactivity in Swedish topsoil after the explosion in the Ukraine naturally caused considerable confusion. Similarly, assessments of the technical possibility of bringing the sunken ferry to the surface, as well as conflicting views on the ethical acceptability of doing so, are difficult for the public to grasp - both because of lacking expertise or background knowledge and because of technical terminology in the information and arguments, that are put forward.

Differences in risk perception are, if possible, even more problematic in such circumstances. It has to do with what was said in connection with the so-called "white male phenomenon" above. Several studies have shown that experts who are responsible for designing and/or monitoring projects that involve risk often define the risks involved more narrowly than laymen do. Experts' definitions presuppose carefully demarcated and specific definitions of risk and usually result in definitions of risk as the product of the factors, probability and (extent of) the consequences of a given threat; laymen, on the other hand, perceive risk as having more dimensions and aspects (Slovic 1987). Furthermore, risk factors are valuated differently by different individuals (DrottzSjöberg 1991). Renn et al. (1992) write, for example: "[A]n exposure of a few people resulting in numerous casualties is likely to be less influential for risk perception and public response than an exposure of many people that results in minor injuries or only 
a few casualties" (154, cf.also 156). Other studies have shown public perceptions of risk to be related to what has been termed the "outrage factor" (Sandman \& Miller 1991), i.e., aside from the perceived danger of serious consequences, public perceptions of authorities' risk perceptions and the adequacy of the measures taken also play in.

Mistrust and lack of confidence in authorities can presumably arise in numerous ways in a catastrophic situation or in the face of acute danger. Differences in experts' and laypersons' risk perceptions can lead to public perceptions that the responsible authorities do not take the risk seriously or that their response to the threat is less than the situation requires. Stress and mistrust can arise as much due to the measures authorities take (or do not take) as to the acute stress and fear that exposure to danger entails (Hallman \& Wandersman 1992). Low levels of confidence need not even have to do with the decisions and measures taken, but can sometimes be the result of latent distrust. Such a mood can have two causes: (1) the layperson's awareness of his/her subordinance vis-à-vis authorities in terms of knowledge and information, and (2) a suspicion that the authorities may not be forthcoming with all they know about the situation in cases where they may possibly have been remiss in their responsibilities. If, furthermore, conflicting information and recommendations are in circulation while, at the same time, the public is urged to remain calm, the result may be quite the opposite of what experts have calculated: the risk may be perceived as greater rather than less (Nohrstedt 1988).

\section{Authorities' Risk and Crisis Communication}

'Authorities' are, of course, human beings, and how they or other organizations act and react in a catastrophe or severe emergency can vary in much the same ways as the general public's behaviour does. Apathy and exaggerated responses may occur in these environments, as well. What we shall be considering here, however, is the body of research that documents the behaviour of public authorities in crisis, how crises impact on the organizations, and the lessons to be learned from past experience. Unless otherwise credited, the discussion relies heavily on Flodin (1993).

Organizations of this type have the following typical characteristics: their performance is highly goal-oriented with well-defined objectives; the organization's sphere of authority is clearly delimited and its performance regulated in law; 'performance' in these cases means the exertion of legal authority, i.e., power. Acute emergencies generally mean that the day-to-day activities of the organization must adapt to the special tasks the situation requires, which may imply rather thoroughgoing changes. The extent of these demands and the organizations and institutions involved will vary according to the nature of the emergency. A major fire on land usually activates fire-fighters and rescue organizations in a more or less predictable fashion; a major fire at sea poses another, more difficult challenge. And so forth.

Some studies make a distinction between major accidents and catastrophes in terms of the communication requirements the two classes of emergencies make. In the face of catastrophe organizations have quickly to establish contacts with new partners and develop new forms of cooperation that lead the organization beyond the bounds of its normal duties. There is a surge of information - both incoming and outgoing - that has to be processed and expedited, all the while issues of specialist competence and problems of coordination have to be solved. The organization's ability to be flexible and adapt quickly to extraordinary circumstances is put to the test. The situation may require new duties which in turn require changes in the organizational structure. Perhaps the prime 
deviation from normal routine is that responsible authorities, institutions which normally communicate along vertical lines, are forced to deal with horizontal flows in the form of urgent questions from and information to mass media and the public. The change, moreover, must be effectuated without delay.

The information provided by authorities should, of course, live up to high standards of both accuracy and immediacy - which are not always easily combined. The following 'laundry list' is an attempt to systematize what the public has a right to expect of the information public authorities put out in an emergency situation (Guttling \& Wiegman 1996). (No order of importance is implied.) It should be

- credible

- reliable

- clear and comprehensible

- immediate

- legitimate.

The list is hardly exhaustive, and the terms overlap somewhat. Still, it highlights some of the central features of the responsibility authorities must shoulder in emergency situations. It should be noted that no firm distinction is made here between public perceptions of the message and perceptions of the sender. Credibility is closely related to how the source of the information, the sender, is regarded. Information will be credible provided it comes from a legitimate source, i.e., a body that is authorized to provide information in the kind of situation that is at hand and whose competence or expertise is recognized. Obversely, we can expect information from a non-legitimate source whose competence is unknown to be less credible. Information from a 'grassroots' source that is contradicted by authorities' information - all else equal - will not be accorded the same credibility as what authorities say.

Reliability is achieved when the information one provides proves to be accurate/true, consistent and relevant. Accuracy or truth is clearly the crucial factor here. There is nothing so destructive of confidence than to be 'caught in a lie', or, as Harrison (1999) puts it: "From the point of view of the organisation's reputation, being found out in some kind of cover-up is the kiss of death" (24). Inconsistencies - when different messages from the sender are not in total agreement - are not as damaging as misrepresentation or untruths. An authority can still enjoy public confidence if the reasons for any discrepancies are made clear. 'Coming clean' with such information is a test of the communicator's moral fibre; one is always tempted to suppress information that conflicts with one's previous statements. The importance of relevance is illustrated by the common observation that politicians are expert at 'ducking' pointed questions, that is, the answers they give sometimes have little to do with the question. The public authority who behaves in such a manner in an emergency or risk situation will find it very difficult to maintain its credibility and reliability in the eyes of the public.

Clearly, information to the public (or other intended receivers) should be clear and comprehensible. This is sometimes easier said than done. Sometimes the problem is the above-mentioned gap between experts and laymen. Furthermore, the public is highly heterogeneous, with widely varying verbal skills. The range may become even wider as our societies become increasingly multicultural. 
Catastrophes and emergencies often arise suddenly, which makes it important to issue warnings and recommendations immediately, without delay. Speed of delivery is not always compatible with goals like accuracy and comprehensibility (see further below).

Legitimacy means that the authority's information should be perceived to be compatible with morally acceptable objectives. Here, above all, perception of the message depends on the reputation of the sender. Perceptions of the legitimacy of the message relate to both message and sender. Some characteristics that are decisive with regard to perceptions of the sender's and the message's legitimacy are that the message relates to the needs and circumstances of victims and others affected by the catastrophe, i.e., that the sender/message displays some empathy and compassion, and that the communicative situation is characterized by openness. Obviously, these features are closely related to the broader concepts of 'risk' that laymen apply, compared to the narrow ones experts use and to the phenomenon of 'outrage' referred to above.

On the whole, research in this area shows a growing interest in aspects that relate to what in the field of rhetoric is known as the 'ethos' of the risk information. Even research on planned communication and public relations have contributed insights of relevance to risk and crisis communication. Some conclusions are briefly summarized in the following.

Two traditions within communication research that have quite different roots have come to approach one another in an interesting manner in recent years. Jürgen Habermas' (1990) theory of communicative acts, with roots in the critical theory of the Frankfurt School, posits a fundamental distinction between communicative and strategic acts which may be used as starting point for analyzing communication processes. Habermas operates with ideal-types, that is, he describes pure forms, whereas in empirical reality only imperfect, hybrid forms of the phenomena will occur. The idea is not to use these terms to classify some information as communicative and other as strategic, but rather to apply them analytically to help judge the potential of different messages to fulfil the criteria outlined above. Communicative acts are, Habermas writes, oriented toward understanding; the parties to a conversation or exchange strive to achieve agreement and a common outlook. In the case of strategic acts, on the other hand, the goal is not agreement or consensus; here, one of the parties - perhaps both - strives to realize his/her own agenda. Even in such cases the result of the interchange may be agreement and a common outlook, but the strategic actor will not be willing to modify his position if it conflicts with his personal interests. Consensus will be reached, if at all, through adaptation on the part of the other party. According to Habermas, communicative acts are characterized by a special openness, namely, that both parties are prepared to redeem their 'claims to validity'. In other words, they are prepared to explain their standpoint.

Public relations researcher James Grunig has been quite influential with a so-called theory of excellence, whereby the most effective information programmes are those which are two-way and symmetrical (Grunig \& Hunt 1984; Grunig 1992). One can hardly equate Habermas' communicative acts with Grunig's two-way, symmetrical information. The latter's background in systems theory and its relatively rudimentary conception of the dialogicity of the communication (Larsson 1997) place Grunig's information in the category of tacit or latent strategic acts rather than a communicative one in Habermas' sense. Nonetheless, both Grunig and Habermas point to a crucial factor that decides whether a communicative process resultsin relationships of trust, viz., the power relationships that prevail in the communication situation. 
Peter Sandman, a leading researcher and consultant in the field of risk communication, reaches similar conclusions regarding the importance of openness and dialogue for the success of communication, particularly in connection with risks and threats. Sandman's theoretical background is neither Habermas' communicative acts nor Grunig's model of two-way symmetrical interchange; instead, his ideas are based on findings relating to risk perception. Like the other two, Sandman emphasizes the importance of dialogue and responsiveness, but he also points ahead to a next crucial aspect: "The cutting-edge risk communication question today is no longer how to communicate with the public about risk; we have moved a long way toward answering that one. The cuttingedge question is how to become the sort of organization that can do it" (Sandman 1992).

Sandman touches on what is undoubtedly the weakest link in the chain between research findings and concrete practices in the field. There is apparently a great deal of inertia to be overcome before findings can be put into practice. Several studies have found that contingency planning for possible catastrophes often has low priority and that the lessons of painstaking evaluative studies are often ignored. As a Swedish government 'Commission on Threats and Risks' wrote in 1995: "Very little has been done to prepare for the great volume of information output that serious situations of the kind the commission has studied will require" (SOU 1995:20). A recent review of a number of major accidents in Great Britain during the 1980s found that several of these accidents might have been prevented, had one learned the lessons of previous catastrophes (Young 1999). A Swedish study of local authorities' information preparedness found that awareness of the need for such preparedness was keen, but that it "had not been translated into detailed information plans, specially trained staff and realistic drills" (Dahlström \& Flodin 1998). Handbooks and practical recommendations in the area stress the importance of planning risk and crisis communication in order to avoid errors and to minimize secondary injuries and damage (Chess et al. 1990; Covallo 1987; Dahlgren \& Flodin 1998; Harrison 1999; Regester 1987). There are, of course, reasons why politicians and authorities may be hesitant to commit considerable sums of public funds to improving the standard of preparedness for catastrophes - other, more imminent needs cannot be ignored, the risk of a catastrophe is only a statistical probability, and should a catastrophe happen, it will most probably be long after the current term of office has expired, etc., etc. Although the reasoning is understandable, in the longer term there is no justification for turning a blind eye to the information and leadership responsibilities authorities will have to shoulder in the event of a catastrophe or emergency situation. The lessons from the fall-out from Chernobyl and the sinking of the M/ S Estonia are prime examples in this regard (Amnå \& Nohrstedt 1987; Larsson \& Nohrstedt 1996). In retrospect, it seems that Swedish crisis and catastrophe preparedness was in some respects better thought-through among companies in the private sector than among public authorities (cf. Lundin \& Nohrstedt 1995).

The objectives of risk communication and crisis management listed above are fairly straightforward and simple in theory and principle. Neither are they controversial in any way. But putting them into practice is often much more difficult. Harry Otway and Brian Wynne summarize the kinds of problems associated with successful risk communication. They do so in terms of a set of paradoxes which, they contend, are neglected by the dominant risk communication paradigm (Otway \& Wynne 1989; cf. Flodin 1993): 
- The reassure-but-warn paradox: It is not unusual for authorities or information officers to have to accomplish two quite disparate goals in one and the same communication. For example, they may have to persuade a group of people to accept certain risks that are considered 'necessary', i.e., unavoidable, while making the nature of risk involved quite clear. For example: if a processing plant for hazardous wastes needs to be localized in a populated area, residents need to know what to do in case of an emergency. The task is to convince them that the risk is small, yet great enough that they need to be 'prepared for the worst'.

- The paradox of the target-tailored message: Effective information should be adapted to the needs of the target group addressed. In cases where the risk is great enough that it can be expected to affect large sectors of the population - e.g., ionizing radiation leaking out of a nuclear reactor - problems of credibility may arise if the message directed to nearby residents differs from the information directed to the population as a whole. If the operators of the reactor advise nearby residents about what to do in case of a so-called excursion, but do not inform those whose homes lie just outside the primary risk zone, the difference may be perceived as an inconsistency and suggest that the operators are trying to keep something from the public at large.

- The paradox of information cultures: Every organization has a more or less specific information culture, which includes vocabulary, channel preferences and so forth. The established pattern makes it easier to handle information flows under normal circumstances, but in emergencies, when the organization needs to collaborate with entirely new partners with information cultures of their own, established routines can be a hindrance, particularly if one party has an authoritarian and secretive culture, and the other a decentralized and open culture.

- The need-for-information paradox: Often, responsible authorities find it difficult to attract the public's interest when they try to inform them about possible dangers, but once a catastrophe has occurred the public's need and desire for information is virtually insatiable.

- The 'body-language' paradox: In concrete situations information is often equivocal and can be interpreted differently, not least in cases where what seems to authorities to be clear and unequivocal is perceived by members of the public to be diffuse and contradictory. The problem is particularly acute when authorities behave in ways that seem to contradict what they say. One example of such inconsistency occurred immediately after the fall-out from the Chernobyl catastrophe in 1986, which affected parts of Sweden a great deal. Authorities told dairy farmers to keep their cows in the barn due to the fall-out; meanwhile, the general public was being told that there was no need for alarm. Not surprisingly, many people found this contradictory. A newspaper in Gävle (the largest community in the hardest-hit regions) carried the following headline: "RADIATION SUBSIDING ... BUT COWS, BEWARE!" (Gefle Dagblad, 3rd May 1986).

- The confidence/alertness paradox: In cases where the responsible authorities enjoy a high degree of public confidence it can, paradoxically, make it difficult to keep the public alert to imminent danger so that those in danger can act quickly and effectively should the situation become acute. In other words, public confidence that authorities can and will master a situation is not an unmixed blessing - not if it means that people relax when they should be watchful. 
- The accuracy/frankness paradox: Referring to the goals of risk communication mentioned earlier, this paradox means that it is not always enough that one's information is correct, if the sender does not also warn the public that it is preliminary and perhaps incomplete. Once again an example from the Swedish handling of information about the caesium contamination after Chernobyl is illustrative. Once the source of the radioactivity was determined to be fallout from the Ukraine, the Swedish Radiation Protection Institute (SSI) announced that the levels were two to three times natural background radiation. The next day, SSI announced that radiation in some places might be ten times natural background radiation. Three days after the initial announcement, SSI said that in certain 'hot spots' radiation might be up to one-hundred times natural background radiation. All three messages ended with the comment that the levels were "low enough not to require any special measures". The problem was not that SSI's information was inaccurate or that their interpretation of it was unreasonable. On the contrary, the data were quite accurate and the interpretation well-founded. The problem was that SSI made the first announcement without telling the public that the data were preliminary and incomplete. Failure to do so caused confusion as the picture became more detailed and SSI revised the data upwards. Worried people in the areas concerned presumably got the impression that SSI did not really know what the situation was, but wished to keep them calm at all costs (Nohrstedt 1988).

A second, fairly common reason why an organization - be it an authority or private company - might be less than frank regarding possible errors or misjudgments is the risk that such an admission might lead to criminal or civil proceedings in court (Harrison 1999).

The paradoxes above point out several difficult conflicts that must be resolved when an organization has to communicate about risks, catastrophes or crises. Past experience suggests that numerous problems arise concerning authorities' interaction with the general public and mass media in these kinds of situations. The Norwegian government's study of the aftermath of Chernobyl (NOU 1986:19) notes the following conflicts relating to the objectives and operations of authorities and mass media:

- Time: Responsible authorities generally give priority to completeness and accuracy of their information; they therefore often wish to wait for more details before issuing a statement; media, on the other hand, want information fast.

- Sources: Responsible authorities prefer for the media to carry their information and judgments, whereas journalists are trained to seek out a variety of sources.

- Responsibility: Authorities are legally bound to provide correct information that does not cause harm. Media are freer; they can let the public be the judge of the value of their content and leave it to them to draw their own conclusions.

- Knowledge: Experts generally describe the situation in all its complexity; they wish to specify degrees of confidence and so forth. Journalists want to popularize and simplify; nor do they always understand the experts' jargon.

- Priorities: Media and authorities do not always agree regarding what information it is most important for the public to know.

- Credibility: A credibility crisis may arise if in the confusion surrounding an acute situation authorities provide information that subsequently proves inaccurate or in- 
correct. Mass media may not trust the institution's information further along in the course of the event.

Toward the end of this review we shall consider a number of crisis scenarios in which conflicts of these kinds figure and contribute to the course events take.

\section{The Role of the Media in Catastrophes}

In a well-known review of mass communication theory Dennis McQuail (1989) set out a conceptual model in which he refers to the system of normative and legal preconditions for media activity as "the media institution". These include organizational and professional prescripts for mass media messages, here primarily news reporting. In the following I shall highlight contradictions and complications inherent in crisis and catastrophe communication via mass media and journalists, with an emphasis on news copy. (Unless otherwise noted, the material is based on Nohrstedt \& Nordlund 1993 and sources cited there.) Mass media and journalists play complex roles in society, and they are subject to a number of criteria that are not always compatible. As a result, individual editors and journalists are often confronted with difficult decisions and dilemmas.

What are the main difficulties media and journalists face in connection with emergencies and crises? Here we shall confine our attention to the major problems which research has identified and documented. They are representative of the kinds of conflicts journalists reporting catastrophes and conflicts can find themselves in, due to inherent contradictions in their own roles and expectations regarding their performance:

- Channel of information or Fourth Estate? The equivocal role implicit in the term, "Fourth Estate", calls attention to perhaps the most fundamental conflict in journalism. On the one hand, the media - especially news reporting - is expected to provide a channel that conveys vital information to all sectors of society, thereby helping to strengthen social cohesion. This role entails expectations on the part of government that the public be kept abreast of decisions and policy, but also an implicit expectation that the media have a share in the responsibility to maintain and preserve the fabric of society. These expectations come to the fore in emergencies, when vital information regarding current risks as well as recommendations and orders regarding measures and behaviour need to be communicated without delay to the entire population.

On the other hand, the status of "fourth estate" implies that the media should maintain their indpendence vis-à-vis government and critically scrutinize the exercise of power, the wisdom of public policy and the moral conduct of individual public figures. It is an essentially adversarial role, whereby the journalist gives the public a factual basis for their democratic participation as citizens. Under normal circumstances this latter role is quite self-evident, but in the face of a catastrophe, maintaining the independence of the media voice is at once both difficult and problematic. Journalists face difficult decisions. What is a reporter to do if he or she discovers that the rescue and clean-up operations after a major nuclear accident might have been handled better, because, for example, the responsible authorities had made an all too optimistic prognosis so that the measures implemented proved inadequate? Should the criticism be raised while the situation is still acute - which might make rescue operations even more difficult by lowering people's confidence in authorities, thereby raising the level of anxiety? 
One thing is certain. There is no patent answer. The problem must be tackled with specific reference to the situation at hand by the medium and the journalist directly involved. The decision reached will depend on the role the medium/journalist chooses to play, and that choice will have been affected by any number of factors. Is the emergency still acute, or has the situation stabilized? Have people begun to process their experiences mentally, to integrate them into their memories in order to move on? What kind of medium does one represent - public expectations vary, for example, with regard to the press and broadcast media. There is, for example, generally greater acceptance of delays in the case of print media.

- Speed or accuracy? Catastrophes and crises often bring the latent conflict between reporting as quickly as possible and reporting as accurately as possible to a head. The conflict is genuine; the goals are contradictory, and a balance must be struck between the two. Journalists follow one of two strategies. The first one is to strive for speed and report all available information immediately. The task of evaluating the reliability and implications of the information is left to the receiver, i.e. in most cases the individual citizen or resident. The problem with this strategy is that it may lead to a reaction on the part of the public to "act first, ask later". The other strategy puts priority on accuracy and prescribes confirmation of facts before publication. In this case the medium/journalist takes responsibility for the reliability of the message. The problem with this strategy is that the confirmation and evaluation process may mean that the information reaches the public too late to be of any use.

- Understanding or entertainment? Mass communication researchers sometimes speak of a 'logic' of the media - albeit not always entirely consistently and with the same meanings. But the basic idea is that the conditions under which media operate give rise to certain modes of presentation which are frequent enough to be called 'typical'. One might also call it 'media dramaturgy'. Information is shaped according to stereotyped moulds: polarization, sensationalism (i.e., emphasis on aspects that are arousing, but not necessarily significant), personification, and story-telling, i.e., constructing a narrative structure with constitutive elements like 'problem - climax resolution'.

The reasons why media choose narrative forms that have these characteristics may be several. For one thing, the standard form may make it easier to reach the great variety of individuals (having different degrees of background knowledge, etc.) who make up mass audiences. Furthermore, dramaturgic techniques - as the name implies - heighten the dimension of psychological involvement and human interest.

In cases that are dramatic in themselves, however, such features can get in the way of conveying information and an understanding of the events at hand. A drastic and simplified form of presentation, which the media regularly use to arouse readers' interest, can make it harder to get important nuances across in a stressful situation ("RADIATION SUBSIDING ... BUT COWS, BEWARE!").

A special reflection of the dilemma is the empirically documented fact that dramatization of news events tends to increase with the geographical distance from the event.

- News value or follow-up? A fourth conflict has to do with various media's time frames in news reporting. A frequently heard criticism of news journalism is that journalists rush from one event to the next and seldom stop to give what they cover any deeper thought. Since news media tend to equate novelty with news value, news 
journalists tend to lose interest in long, drawn-out processes. A catastrophic earthquake will, for example, be given thick, black headlines on the front page in its acute phase, but its aftermath will receive no coverage at all - which means that neither will evaluations and possible lessons for the future be covered. This conflict between news value and follow-up - which, parenthetically, also clearly imposes limits on the media's watchdog function - is what underlies recurrent complaints about news media's "short attention span" or chronic lack of historical perspective. In the case of crises and catastrophes, this tendency toward the novel means that the media fail to encourage the kinds of evaluations and analyses which they may have called for in earlier phases of the event.

\section{Phases of Media Reporting}

As noted earlier, a principal finding concerning media coverage of catastrophes and emergencies is that the media focus intensely, but briefly on such events. Joseph Scanlon (1980), among others, describes media interest as being virtually totally confined to the acute phase - a phenomenon he refers to as "the Big Bang". One should, of course, be cautious about making sweeping generalizations. Media work differently. Coverage will differ depending on the relation of the medium to the threat or event. Does it affect one's own readers, etc., or only people far away? That said, the fact remains that "the Big Bang", generally speaking, is accorded high news value and will therefore receive a lot of coverage.

Not surprisingly, research interest mirrors the media's tendency to focus on the acute phase of emergencies. Earlier phases and the aftermath have received considerably less attention. Something can be said about media behaviour in the warning phase, however.

Several studies have documented the media's, particularly local media's, role in warning the public of imminent threats. This has been noted both when authorities have turned to the media and asked them to convey the message and in situations where the media are the first to be aware of the threat. These latter cases can be problematic for the responsible authorities inasmuch as they do not have the initiative from the start. It can prove difficult to answer journalists' questions, and the risk of contradictory messages is relatively great. Meanwhile, it should be pointed out that the media's prompt communication of information has on numerous occasions proved a valuable asset to authorities and operative personnel in the field. The Swedish response to the Chernobyl catastrophe is a case in point: authorities at lower (local) levels received information from central (national) authorities via Swedish mass media. American studies have found that in some cases responsible authorities have become aware of the full extent of a catastrophe thanks to media coverage.

In the acute phase the media play an important role, conveying information to and from authorities. But the research also includes some examples of negative effects of media activity in connection with acute emergencies. Probably the most interesting issue regarding the role mass media play in crises and catastrophes concerns the extent to which their coverage makes the situation more difficult - in cases, for example, where media coverage is exaggerated or contains misinformation. That the media may exaggerate or spread inaccurate information is clearly bound up with an assumption that a journalist's prime motor force is to seek out sensational material. One facet of this problem complex is the media's tendency to focus on destructive and irrational behaviours such as panic, plundering or raw egotism among the victims of the catastrophe. Experi- 
ence shows that such reports create and help spread myths, inasmuch as such behaviours are relatively rare and, when they do occur, they are hardly representative of the victims as a group (Quarantelli 1988). Here, too, one must be cautious about generalizing. Not all media contribute to myth-mongering, certainly not to the same extent, in any case. There is mounting evidence to the effect that tendencies in this direction tend to grow stronger, the further away from the scene the medium is. Myth-mongering is most common in coverage of distant catastrophes (Goltz 1984). This is consonant with an impression that is widespread among Swedish journalists working for local media, namely, that their colleagues in nationally distributed media are much less sensitive to how exaggerated or melodramatic reports may impact on the victims and residents of the stricken community.

Some studies have found that journalists operating under stress, when the demand for information has reached a crescendo, may dispense with or lower their level of ambition to check their sources and confirm their stories. In states of acute emergency radio stations open their doors to any and all kinds of information. In one review of the literature, this overall view is specified somewhat: the waiving of quality control measures known as 'gate-keeping' and editorial oversight in states of emergency is common in broadcast media, but not in print media, where the tendency is the opposite, toward tighter controls (Wenger \& Quarantelli 1989).

Paradoxically, it has been pointed out that some errors in news reporting may be due to overly cautious behaviour on the part of the media: in the acute phase of an emergency the media limit their reporting to the often quite scant information that authorities have received. It has been pointed out, however, that the so-called 'command-post perspective' may be overrepresented among cited sources inasmuch as the media always mention official sources, but do not always attribute material gleaned through unofficial and informal channels. Be that as it may, radio reports appear to be based to a considerable extent on information from the public.

There is also reason to mention the more direct operative problems that media activity in connection with crises and catastrophes can cause. Intrusive reporters can get in the way of rescue operations, etc. Disaster research has noted the stress caused by the gathering of large groups of people at and around the scene of a catastrophe - in many cases well-meaning individuals who wish to help investigators by providing information and so forth. But for unprepared authorities, the crowds can be a nearly unmanageable burden. The onslaught of journalists can also cause friction, especially among organizations which are short on information staff, as both the Harrisburg and Chernobyl events testify to. Media reporting causes other forms of stress, as well. A phenomenon mentioned earlier is the rush of private communications that news of an accident or catastrophe elicits among the populace; people contact friends and relatives in the area to verify and to complement the reports they have heard. This clogs both the telecommunications and traffic infrastructures.

In addition, on some occasions media and journalists go beyond helping authorities gather information and take on operative tasks that normally are the public authorities' responsibility. In emergency situations radio stations sometimes carry communications between rescue units and organizations, and when operative personnel have too much on their hands, contacts with national media have on occasion been delegated to journalists from local media. In connection with acts of terrorism the media have even helped spread false information in order to mislead the terrorists. 
A review of the research literature on media behaviour in the acute phase of emergencies (Nohrstedt \& Nordlund 1993) found a quite varied picture. The following conclusions were drawn:

- Immediate, directly transmitting broadcast media play a more important role as channels of communication than print media.

- Local media near the site of a catastrophe will relate to the event differently than more distant national media.

- News reporting about a catastrophic event may be fragmentary, but the event may be shown and explained in greater depth in other material, e.g., features and documentaries.

- Media and authorities can collaborate actively and fruitfully to help manage acute emergencies.

- In other instances, mass media can hinder the implementation of a measure through thoughtless and irresponsible behaviour.

- Media can cause credibility crises between the public and responsible authorities both by uncritically conveying their messages and by subjecting the authority's every message and every measure to critical scrutiny.

With regard to the aftermath, the phase of mental processing and physical reconstruction after a catastrophe, there is an aspect of media behaviour that research has identified, namely, a reaction or 'pendulum swing' on the part of the media in relation to their behaviour during the acute phase of the event. As mentioned above, the scrutinizing function is often toned down or even suppressed during the acute phase of a catastrophe. This - in most cases a quite reasonable response - may lead to compensatory behaviour in the aftermath if journalists feel they perhaps should have been more critical earlier on. In such cases the media may become overly fault-finding and start looking for scapegoats. Studies of Swedish media's follow-up coverage of the radioactive contamination of parts of Sweden after the Chernobyl catastrophe have found instances of such compensatory behaviour.

A critical role is an integral part of journalistic media's role, and it is natural that criticism of authorities' measures be raised once the worst of the catastrophe is past. Media criticism can help improve performance in the future. This represents a vital service to democracy, which means that the tendency to concentrate on "the Big Bang" and then rush on to other, more pressing issues is problematic.

\section{Emergency Turns Into Crisis: An Interactive Model}

So far, we have treated this field of research inquiry as consisting of separate sectors like disaster research, risk perception, and crisis communication, respectively. Such a typology reflects the respective academic perspectives from which researchers approach the subject. But my intent here is to try to integrate the knowledge from these different fields into a single, comprehensive model. Thus, in the following I shall interrelate the various research findings in plausible scenarios, whereby crises arise in connection with catastrophes and situations of extreme risk.

First of all, for the sake of simplification we may consider crisis development processes as the result of the interaction of three groups of agents: authorities - media - citi- 
zens. Theoretically, this means that the explanatory factor behind crises has to do with problems in the communication between these parties, which arise because the respective parities have different and partly conflicting agendas, priorities and expectations. Crises of confidence, etc., can in turn threaten basic values or damage the credibility of social institutions. Applying such an interactional perspective, we may see crises as arising out of public anxiety, out of sensationalism on the part of news media, or out of blunders or shortcomings in authorities' performance. Naturally, all three factors or combinations of any two are also possible, but for the sake of clarity we shall deal with the respective causes separately in the following scenarios.

1. Public anxiety leads to crisis. Here the causal mechanism lies in irrational reactions to the catastrophic event on the part of laymen and the general public. The scenario may be outlined in the following steps: (a) people generally do not take measures to protect themselves against possible risks; (b) they lack background knowledge about the threat, its consequences, and how they can avoid danger; (c) they become confused and overly stressed by contradictory messages from different sources, (d) they react in panic, which exposes them and others to yet greater risks, (e) this reaction makes it even more difficult for the responsible authorities to manage the situation; (f) mass media criticize the authorities for their failure to manage the situation; and $(\mathrm{g})$ the public begins to doubt the authorities' competence and ability to deal with the situation, which makes their task even more difficult.

This scenario is fully conceivable, yet a number of observations speak against it. Although people generally do not take measures to prepare themselves for possible catastrophes, they seldom become panic-stricken and react irrationally when catastrophe strikes. They have an acute need for information, and they do have problems sorting out contradictory messages from different sources, but in most cases - except for situations of life-threatening danger with no time to think - their behaviour is rational. They may not always follow authorities' directions or recommendations, but that should not be confused with panic or irrationality, even if it may make authorities' work more difficult. And if public opinion turns against the responsible authorities, it is more likely a consequence of how they have met the public's need of information earlier on, than that they have been made scapegoats for the problems caused by irrational reactions on the part of those stricken.

2. Media sensationalism is to blame. In this scenario the root of the problem is the way mass media handle information in the early phases of the emergency. The media's reporting of unconfirmed rumours, hysterical opinions and the complaints of anxious citizens, together with exaggerated estimations of the threat at hand, lead the public to conclude that authorities are not taking the threat seriously enough. The citizens lose faith in the responsible authorities and turn instead to alternative sources who claim to have access to more initiated and more accurate information about the risks involved. Authorities lose the public's confidence and therewith their ability to deal with the situation at hand, thus living up to the public's negative expectations - a kind of self-fulfilling prophecy. As a consequence, the public blames the authorities for failing to manage the emergency. Picking up momentum, the spiral of crisis spins on.

This scenario is also fully conceivable, but here, too, the empirical evidence does not fully support it. First of all, we have no immediate reason to believe that the media will prefer to report what alternative or unofficial sources have to say - unless, of course, 
official sources are extremely tight-lipped. The public's acute thirst for information naturally leads especially broadcast media to open their microphones to a wide variety of sources, but they are generally careful to note the status of the report or source in question. Neither do we have any conclusive evidence that members of the public are unable to sort out contradictory information, even if they are sometimes quite frustrated by it. There is also a desire among media, particularly media close by, not to worry their audiences unduly. To the contrary, research findings indicate that journalists frequently adopt the perspective of the responsible authorities - the so-called "command post-point of view" - in the acute phase of catastrophes. They share authorities' assessments of the situation and do what they can to help authorities in the rescue and clean-up operations. Only later, in cases where a crisis of confidence is already budding, can media reporting sometimes turn into a hunt for scapegoats.

3. Crises arise in response to authorities' shortcomings. Having argued against the first two scenarios, what support do we find for the thesis that crises arise because of errors and shortcomings in authorities' and organizations' manner of dealing with the emergency in question?

First of all, a fundamental paradox that characterizes 'the risk society' is at play here, namely, that whereas awareness of various risks and threats has increased among the public at large, the gap between experts and the lay public gapes ever wider. This is perhaps most apparent with respect to threats like radioactive contamination, the greenhouse effect and climate change, acidification, and so forth. Most people have neither the knowledge nor the equipment that is required to assess the threat, even as it relates to themselves.

This situation of dependency gives rise to a latent suspicion of responsible organs and exerts, a feeling that they might not be telling the whole truth, that they may be abusing the power their expert knowledge gives them vis-à-vis the public. Inasmuch as the public actually is quite dependent on the judgments experts make, one cannot dismiss this suspicion as irrational. Seen from the individual citizen's point of view, it is a quite rational response - no matter what experts may think about it and whether or not the reaction is well-founded in relation to the facts of the matter.

These factors - dependency and the 'knowledge gap' - may help explain the relative complexity of laymen's risk perceptions in relation to experts' judgments as documented in research. Given this complexity, it is perhaps not surprising if experts' information to those involved in, say, an environmental catastrophe of some sort seems inadequate in relation to the threat as members of the public perceive it. To solve this problem, and to reduce the degree of suspicion of the responsible authorities, demands that the public - or at least those who are directly concerned - be given access to 'a second opinion' - other information against which they can check the information and assessments their authorities have issued. It is a question of openness. The decisive factor is how authorities react to this need.

One cannot exclude the possibility that authorities will respond in a way that in fact worsens the situation. The reason is an observed tendency on the part of authorities to adopt a communication strategy that is based on the first two scenarios. That is to say, the main objective is to allay the public's fears and to orchestrate (centralize) information output and to avoid journalists, the assumption being that journalists will misconstrue what the experts say and exaggerate the risks. Such a reaction on the part of authorities will most probably elicit precisely the kind of crisis they had hoped to avoid. It 
will lead people to conclude that authorities do not take the situation seriously enough the 'outrage factor' - and that they are hiding something. All of which adds up to heightened suspicion on the part of the public, which makes it harder for the responsible authorities/organizations to manage the situation since they no longer have people's confidence.

\section{A Last Word}

The really difficult lesson for authorities and experts seems to be the insight that they themselves can be a factor that contributes to crisis, that they actually may be perceived as a risk factor by those affected by a catastrophe. This idea is totally foreign to their own self- perception, nor is it compatible with their position of authority, which presumes that it is they, not members of the public at large, who are 'authorities' on the subject. For the media strategist - caught in the middle, so to speak - this self-perception can pose a difficult problem. But it is presumably the media strategist alone who has the capacity to understand the nature of the problem and the competence to solve it.

\section{Translation: Charly Hultén}

\section{Note}

1. An earlier version of the review was included in a government fact-finding study of a tragic discothèque fire in Göteborg in 1998

\section{References}

Allport, G W \& Postman, L (1947/1975) The Psychology of Rumor. New York: Russell \& Russell.

Amnå, E \& Nohrstedt, S A (1987) Att administrera det oförutsedda [Managing the unforeseen]. Stockholm: The National Board of Psychological Defence Planning. (Rapport; 137.)

Beck, U (1986) Risikogesellschaft: Auf dem Weg in eine Moderne. Frankfurt a M: Suhrkamp Verlag.

Chess, C; Hance, B J \& Sandman, P (1990) Improving Dialogue with Communities: A Short Guide for Government Risk Communication. New Brunswick, NJ: Rutgers University.

Covallo, V T (1987) Educating and Informing the Public About Radiation Risks: A Review of Obstacles to Public Understanding. Paper, Workshop on Public Understanding of Radiation Protection Concepts, 30th November-2nd December 1987. Paris: OECD.

Dahlgren, M \& Flodin, B (1998) Informationsberedskap för 2000-talets kriser [Information preparedness for the crises of the 21st century]. Stockholm: The National Board of Psychological Defence Planning.

Drottz-Sjöberg, B-M (1991) Perception of Risk. Stockholm: Center for Risk Research, Stockholm School of Economics.

Finucane, M \& Slovic, P (1999) Riskbedömning och social kontroll - om vikten av att få perspektiv på olika perspektiv [Risk assessment and social control - on the importance of gaining a perspective on different perspectives]. Framtider 18:1.

Flodin, B (1993) Myndigheters kriskommunikation: En kunskapsöversikt [The crisis communication of public authorities: A review of the literature]. Stockholm: The National Board of Psychological Defence Planning.

Goltz, J D (1984) Are the News Media Responsible for the Disaster Myths? A Content Analysis of Emergency Response Imagery. International Journal of Mass Emergencies and Disasters 2(3):345-368.

Grunig, J E (1992) Excellence in Public Relations and Communication Management. Hillsdale, NJ: Lawrence Erlbaum.

Grunig, J E \& Hunt, T (1984) Managing Public Relations. London: Holt, Reinhart \& Winston.

Gutteling, M \& Wiegman, O (1996) Exploring Risk Communication. Dordrecht: Kluwer Academic Publishers.

Habermas, J (1990) Kommunikativt handlande: Texter om språk, rationalitet och samhälle. Göteborg: Daidalos. (Swedish edition of excerpts from Theorie des kommunikativen Handels; Bd. 1-2) 
Harrison, S (1999) Issues. In Harrison, S (ed.) Disasters and the Media: Managing Crisis Communication. London: MacMillan Press.

Howarth, G (1999) Foreword. In Harrison, S (ed.) Disasters and the Media: Managing Crisis Communication. London: MacMillan Press.

Jarlbro, G (1993) Kriskommunikation ur ett medborgarperspektiv: En kunskapsöversikt [Crisis communication from the point of view of the citizen: A review of the literature]. Stockholm: The National Board of Psychological Defence Planning.

Larsson, L (1997) Tillämpad kommunikationsvetenskap [Applied communication science]. Lund: Studentlitteratur.

Larsson, L \& Nohrstedt, S A (red.) (1996) “Det ser verkligen illa ut.” Kommunikationsproblem i samband med Estoniakatastrofen 1994 ["It looks pretty bad." Problems of communication in connection with the sinking of the M/S Estonia 1994]. Stockholm: The National Board of Psychological Defence Planning.

Lundin, N-I \& Nohrstedt, S A (1995) Risk-, katastrof- och kriskommunikation [Risk, catastrophe and crisis communication]. In Larsson, I \& Rosengren, K-E (red.) Kommunikationens villkor. Lund: Studentlitteratur.

McQuail, D (1989) Mass Communication Theory, 2nd ed. London: Sage.

Nohrstedt, S A (1988) Informationskrisen efter Tjernobyl: Ett processperspektiv [The information crisis after Chernobyl: A process perspective]. I Carlsson, U (red.) Forskning om journalistik. Göteborg: Nordicom. (Nordicom-Nytt/Sverige; 4)

Nohrstedt, S A \& Nordlund, R (1993) Medier i kris: En forskningsöversikt över mediernas roll vid kriser [Media in crisis: A review of research on the role of the media in emergencies]. Stockholm: The National Board of Psychological Defence Planning.

Nohrstedt, S A \& Tassew, A (1993) Communication and Crisis: An Inventory of Current Research. Stockholm: The National Board of Psychological Defence Planning.

NOU 1986:19 Informasjonskriser [Information crises]. Oslo: Universitetsforlaget.

Otway, H \& Wynne, B (1989) Risk Communication: Paradigm and Paradox. Risk Analysis 9:2.

Quarantelli, E L (1988) Lessons Learned from Research on Disasters. 1988 Symposium on Science Communication: Environmental and Health Research, December 15-17, Annenberg School of Communication, University of Southern California, Los Angeles.

Regester, M (1987) Crisis Management. London: Hutchinson.

Renn, O; Burns, W J; Kasperson, J X; Kasperson, R E \& Slovic, P (1992) The Social Amplification of Risk: Theoretical Foundations and Empirical Applications. Journal of Social Issues 48(4):137-160.

Sandman, P M (1992) Responding to Community Outrage: Strategies for Effective Risk Communication. Fairfax, VA: American Industrial Hygiene Association.

Sandman, P \& Miller, P (1991) Outrage and Technical Detail: The Impact of Agency Behavior on Community Risk Perception. New Brunswick, NJ: Environmental Communication Research Program, Rutgers University/Division of Science and Research, New Jersey Department of Environmental Protection.

Scanlon, J (1980) The Media and the 1978 Terrace Floods: An Initial Test of a Hypothesis. Disasters and the Mass Media, Proceedings of the Committee on Disasters and the Mass Media Workshop, February 1979. Washington, DC: The National Academy of Sciences.

Slovic, P (1987) Perception of Risk. Science 236:280-285.

SOU 1995:20 Utan el stannar Sverige; Scenarion och överväganden om påfrestningar $i$ det fredstida samhället [Without electricity Sweden stops; Scenarios and thoughts about stress on society in peacetime].delbetänkande av Hot- och riskutredningen, Försvarsdepartementet. Stockholm: Norstedts.

Wenger, D \& Quarantelli, E L (1989) Local Mass Media Operations, Problems and Products in Disasters. Newark: Disaster Research Center, University of Delaware.

Young, P (1999) The Context. In Harrison, S (ed.) Disasters and the Media: Managing Crisis Communication. London: MacMillan Press. 